\title{
Photodynamic Effect of some Phthalocyanines on Enveloped and Naked Viruses
}

\author{
L. NIKOLAEVA-GLOMB ${ }^{1}$, L. MUKOVA ${ }^{1}$, N. NIKOLOVA ${ }^{1}$, V. KUSSOVSKI ${ }^{1}$, L. DOUMANOVA ${ }^{1}$, V. MANTAREVA ${ }^{2}$, \\ I. ANGELOV ${ }^{2}$, D. WÖHRLE ${ }^{3}$, A. S. GALABOV ${ }^{1^{*}}$
}

${ }^{1}$ The Stephan Angeloff Institute of Microbiology, ${ }^{2}$ Institute of Organic Chemistry, Bulgarian Academy of Sciences, Sofia, Bulgaria;
${ }^{3}$ Institute of Organic and Macromolecular Chemistry, University of Bremen, Bremen, Germany

Received July 21, 2016; revised December 8, 2016; accepted July 3, 2017

\begin{abstract}
Summary. - Activity of three photosensitizing phthalocyanine derivatives was tested for photodynamic inactivation towards two coated and two non-enveloped viruses - bovine viral diarrhea virus (BVDV), influenza virus $\mathrm{A}(\mathrm{H} 3 \mathrm{~N} 2)$, poliovirus type 1 (PV-1) and human adenovirus type 5 (HAdV5). In the case of coated viruses, a combination of virucidal and irradiation effects was registered by octa-methylpyridyloxy-substituted Ga phthalocyanine (Ga8) toward BVDV, whereas tetra-methylpyridyloxy-substituted Ga phthalocyanine (Ga4) revealed a marked photoinactivation only. No such effect was observed towards influenza A virus. In contrast, the photoinactivating potential of Ga4 and Ga8 marked very high values on naked viruses, especially on HAdV5, at which both the virucidal as well as the irradiation effects became combined.
\end{abstract}

Keywords: phthalocyanine; photodynamic inactivation; virus

\section{Introduction}

The photodynamic reaction employs a non-toxic dye termed a photosensitizer, which is converted into an excited state by utilizing the energy of visible or ultraviolet light in the presence of molecular oxygen. The excited state triggers the generation of reactive oxygen species or transfers the energy to molecular oxygen leading to the formation of singlet oxygen. As a result, irreparable damages are induced to critical biological targets as proteins, nucleic acids, lipids, etc., whose vital functions are severely impaired. Thus, following such a reaction, microorganisms, viruses included, can be inactivated by the photosensitizing activity of various compounds.

*Corresponding author: e-mail: galabov@microbio.bas.bg; phone: +359-2-870-0108.

Abbreviations: $\mathrm{BVDV}=$ bovine viral diarrhea virus; $\mathrm{CPE}=$ cytopathic effect; Ga4 (GaPc1) = tetra-methylpyridyloxy-substituted Ga phthalo-cyanine; Ga8 (GaPc2) = octa-methylpyridyloxysubstituted Ga phthalocyanine; HAdV-5 = human adenovirus type $5 ; \mathrm{HpD}=$ hemato-porphyrine derivatives; $\operatorname{InPc1}(\operatorname{In} 4)=$ tetramethylpyridyloxy-substituted In phthalocyanine; OD = optical density; PV-1 = poliovirus type 1
The sensitivity of viruses to photodynamic inactivation has been reported as early as in the 1930s (Schultz and Krueger, 1928). Photodynamic inactivation has been clinically applied in treating skin and mucous viral lesions caused by herpes viruses (Felber et al., 1973) and papillomaviruses (Smetana et al., 1997). The pronounced side effects observed in the phototreatment of herpes genitalis in the 1970s (Berger and Papa, 1977) led to its discontinuation (Kaufman et al., 1978). This, along with the development of contemporary potent antiviral drugs, has for a while discouraged wider clinical application of photodynamic antiviral therapy. Nevertheless, the emergence of resistant and even drug-dependent viral progeny after receiving antiviral therapy enforces the search for alternative methods of treating and confining the spread of viral infections, both in terms of therapy and in terms of sterilization of transfusion products.

Recently, with the development of modern photosensitizers and the increment of light technologies, the photodynamic techniques for inactivation of viruses received an ever-growing attention (Costa et al., 2012). The most considerable progress is noted in the viral photodynamic disinfection of blood products (Santus et al., 1998).

The photosensitizing activities of phthalocyanines have been studied from the viewpoint of photoinactivation of 
viruses and have shown promise for sterilization of blood products (Rywkin et al., 1994; Abe and Wagner, 1995). A number of reports exist for a selective antiviral activity of phthalocyanines against HIV (Neurath et al., 1994) or photoinactivation of extracellular HIV with phthalocyanines (Ben-Hur et al., 2000). In addition to studies on HIV, there have been many studies of photoinactivation with phthalocyanines of other viruses, predominantly enveloped, like vesicular stomatitis virus (Moor et al., 1999), Sindbis virus and herpes simplex virus (Rywkin et al., 1994), pseudorabies virus and BVDV (Ben-Hur et al., 2000). The efficacy of photoinactivation varies among enveloped viruses both according to the type of the photosensitizers and type of the virus.

It is well established that naked, non-enveloped viruses are significantly more resistant to photodynamic inactivation than enveloped viruses and the inactivation of viruses like adenovirus, poliovirus, encephalomyocarditis virus or parvovirus has rarely been efficient (Mohr et al., 1993; Wainwright, 2004). Nevertheless, there are photosensitizers that are capable of efficient inactivation of non-enveloped viruses such as enterovirus 71, PV-1, coxsackieviruses A2, A3, A16 and B3 (Wong et al., 2010), hepatitis A virus (Casteel et al., 2004), adenovirus vectors (Schagen et al., 1999), or bacteriophages (Costa et al., 2012). A few reports exist that cite the inactivating activity of phthalocyanines against naked viruses, and in at least one instance a phthalocyanine has been reported to have antiviral activity against the nonenveloped human rhinovirus type 5 in the absence of light (Gaspard et al., 1995).

The present paper describes the effect of newly synthesized phthalocyanines on enveloped and non-enveloped DNA or RNA viruses belonging to different taxonomic families and representing important human and animal pathogens.

\section{Materials and Methods}

Photosensitizers. The following compounds were used: GaPc1 (Ga4), GaPc2 (Ga8), InPc1 (In4) and HpD, the latter used as a reference compound. Compounds were synthesized by Mantareva et al. (2011a,b). The synthetic pathway for synthesis of GaPcl and InPc1 was published firstly by Durmus and Nyokong (2007). HpD was a commercial product of Sigma. Stock solutions with a concentration of $1 \mathrm{mmol} / \mathrm{l}$ were prepared in dimethyl sulphoxide (DMSO) and kept frozen in the dark at $-20^{\circ} \mathrm{C}$. Working concentrations were prepared ex tempore in clear colorless phosphate-buffered saline (PBS) containing $\mathrm{Ca}^{2+}$ and $\mathrm{Mg}^{2+}$.

Light source. A red LED (Lumileads, USA) at $635 \mathrm{~nm}$ was applied, generating a fluent rate of $100 \mathrm{~mW} / \mathrm{cm}^{2}$ and a light dose of $50 \mathrm{~J} / \mathrm{cm}^{2}$ for the irradiation period of $30 \mathrm{~min}$.

Viruses and cells. PV-1 (strain LSc-2ab) of the Picornaviridae (non-enveloped, single stranded +RNA), BVDV (strain TVM) of the Flaviviridae (enveloped, single stranded +RNA), influenza virus A/Aichi/2/68(H3N2) of the Orthomyxoviridae (enveloped, single stranded-RNA) and HAdV-5 of the Adenoviridae (nonenveloped, double stranded DNA) were tested. PV-1 and HAdV-5 were propagated in FL cell line, BVDV in continuous calf trachea cell line, and influenza virus in MDCK cell line. Cells and viruses were from the cell culture collection of the Stephan Angeloff Institute of the Bulgarian Academy of Sciences, Sofia, Bulgaria. Cell lines were grown in a humidified atmosphere at $37^{\circ} \mathrm{C}$ and $5 \% \mathrm{CO}_{2}$ in Dulbecco modified Eagles' medium (DMEM) (Gibco BRL, Grand Island, NY, USA) in a growth medium containing $5 \%$ fetal bovine serum and supplemented with antibiotics (100 IU/ml penicillin, $100 \mu \mathrm{g} / \mathrm{ml}$ streptomycin, and $50 \mu \mathrm{g} / \mathrm{ml}$ gentamycin), and $20 \mathrm{mmol} / \mathrm{l} \mathrm{HEPES}$ buffer (Gibco BRL), the latter providing supplemental buffering to cell culture medium at $\mathrm{pH} 7.2$ through 7.6. Cells were routinely subcultured twice weekly. When harvesting viruses and testing the photoinactivation process, a maintenance medium was used, in which serum was reduced to $0.5 \%$. Maintenance medium for influenza virus contained in addition $3 \mu \mathrm{g} / \mathrm{ml}$ trypsin (Gibco BRL). Viruses were grown in a humidified atmosphere at $37^{\circ} \mathrm{C}$ and $5 \% \mathrm{CO}_{2}$. Virus titration was carried out in cell monolayers in 96-well plates for cell culturing (Cellstar, Greiner Bio-one, GmbH, Frickenhausen, Germany) according to the end-point dilution method (Reed and Muench, 1938). At the end of titration, monolayers were read microscopically, then viable cells were subjected to the neutral red uptake (NRU) procedure (Borenfreund and Puerner, 1985) and the optical density (OD) of each well was read at $540 \mathrm{~nm}$ in a microplate reader (Organon Teknika reader 530, Oss, Netehrlands). The percentage of viral CPE was calculated according to the following formula:

$$
\% \mathrm{CPE}=100-\left[\left(\mathrm{OD}_{\mathrm{D}}-\mathrm{OD}_{100}\right) / \mathrm{OD}_{\mathrm{CC}} \times 100\right]
$$

where $\mathrm{OD}_{\mathrm{D}}$ was the mean value of the ODs of the wells inoculated with the corresponding virus dilution, $\mathrm{OD}_{100}$ was the mean value of the ODs of the highest virus dilution where $100 \%$ CPE was microscopically observed and $\mathrm{OD}_{\mathrm{CC}}$ was the mean value of the ODs of the cell control wells (no virus inoculated). The 50\% CPE was determined by regression analysis.

Cytotoxicity tests. Cytotoxicity of the tested photosensitizers was tested in two different set-ups: the so-called by us (i) dark toxicity and (ii) irradiated toxicity. For the dark toxicity, monolayer cell cultures were inoculated in the dark with $0.1 \mathrm{ml}$ of $0.5 \mathrm{lg}$ serial dilutions of the corresponding photosensitizer and then cells were kept in the dark in the incubator in a humidified atmosphere at $37^{\circ} \mathrm{C}$ and $5 \% \mathrm{CO}_{2}$. At $48 \mathrm{~h}$ post inoculation cells were examined microscopically for visible signs of cytotoxicity and then subjected to the NRU procedure for determining the percentage of viable cells in the sample. For assessing the so-called irradiated toxicity, the same experimental set up was applied, but samples were irradiated immediately after inoculation for a period of $30 \mathrm{~min}$ at room temperature.

Photoinactivation. Aliquots containing $0.1 \mathrm{ml}$ of non-diluted viral stock suspensions and $0.1 \mathrm{ml} 20 \mu \mathrm{mol} / \mathrm{l}$ of substances 
tested were irradiated for a period of $30 \mathrm{~min}$ at room temperature followed by titration of the corresponding virus samples in monolayer of cells for determining the residual infectivity in the sample. Three types of controls were laid: (i) virus control that is not irradiated and not treated with the photosensitizer; (ii) virus control that is irradiated but not treated with the photosensitizer, and (iii) virus control that is not irradiated but is treated with the photosensitizer. The photoinactivation activity was expressed as the margin between the infectious virus titer of the test sample and the controls $(\Delta \mathrm{lg})$.

Statistical evaluation. All experiments were carried out in triplicates with six parallels per sample in the titration set-up. Results are expressed as mean values and standard deviations (SD). Mean values are compared according to the unpaired t-test and $\mathrm{p}<0.05$ was considered statistically significant.

\section{Results}

\section{Cytotoxicity}

Generally, the tested compounds showed very low and almost absent cytotoxicity. The $50 \%$ cytotoxic concentration $\left(\mathrm{CC}_{50}\right)$ defined as the concentration that reduced the absorbance of treated cells by $50 \%$ when compared to the untreated cell control, could be determined neither in the dark toxicity set-up, nor in the irradiated one. Even at the highest possible concentrations tested, the number of viable cells was far above $50 \%$. No detectable differences were observed in the percentage of viable cells in the dark and in the irradiated experimental set-ups.

\section{Photodynamic inactivation, enveloped viruses, effect on} $B V D V$

BVDV represents Flaviviridae family, comprising a diverse group of enveloped viruses with positive RNA genome. BVDV is generally accepted as the surrogate of hepatitis C virus in screening antiviral studies. Interestingly, the mere presence of the tested compounds decreased significantly residual virus titer of BVDV (Fig. 1). This effect was the most significant for Ga8, In4 and HpD. Virus titer was decreased by $\Delta \lg 3.9,2.7$ and 3.4, respectively. That might suggest a selective activity against extracellular virus or against the replication of BVDV in vitro.

Inactivation of the infectious virus after the irradiation procedure varied. It was not significant when compared with the treated but not irradiated controls in the case of Ga8, In 4 and $\mathrm{HpD}$. Only Ga4 was an exception, lowering the titer by additional approximately $\Delta \lg 1.5$. Thus, in total, after irradiation Ga4 was capable to lower infectious virus titer of BVDV by more than $2 \mathrm{lg}$ as compared to the untreated and not irradiated virus controls (Fig. 1). Although no significant difference was observed between the non-irradiated and irradiated samples with $\mathrm{Ga} 8$, the best inactivation results had been achieved right with that compound. Infectious virus titer was reduced by $\Delta \lg 4.16$ (Fig. 1). Expectedly, the virus was not influenced by irradiation itself.

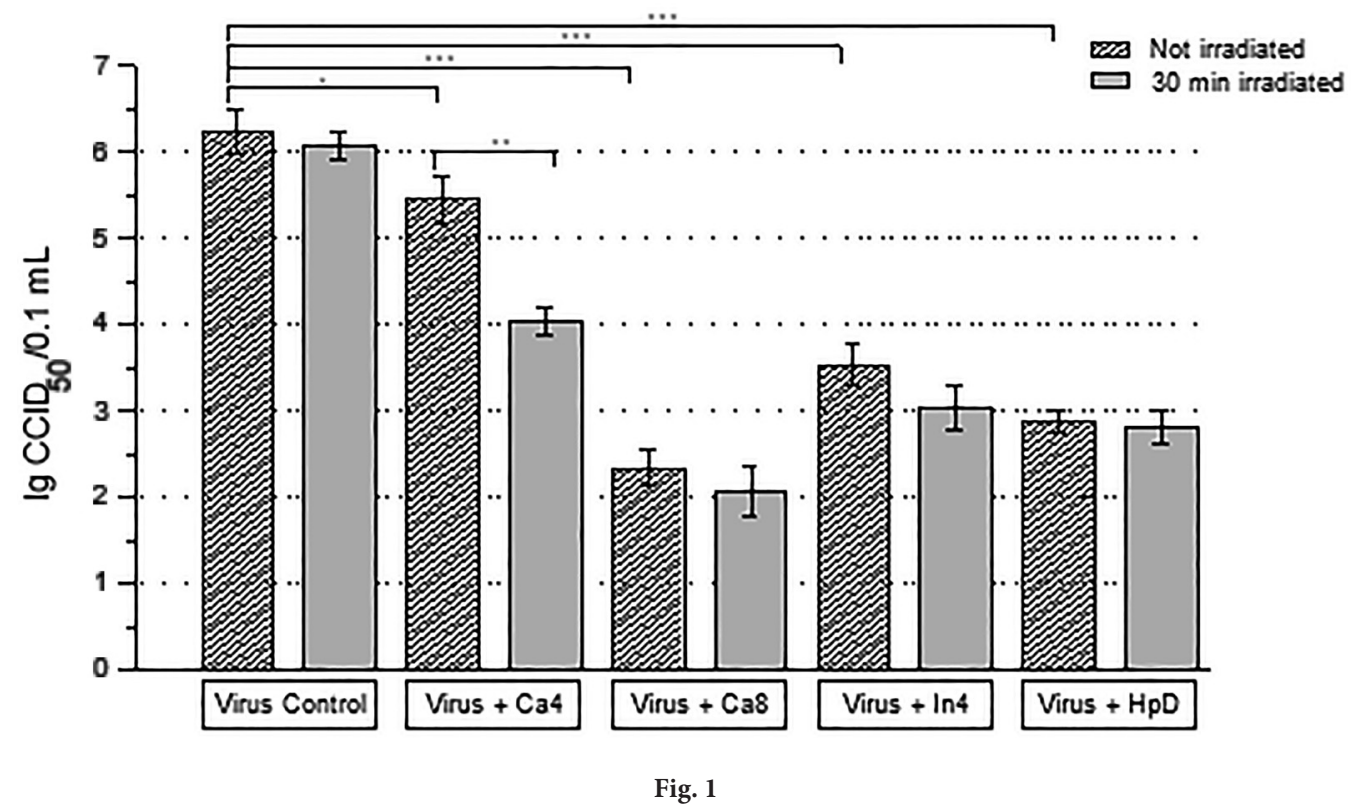

Direct virucidal effect of Ga4, Ga8, In4 and $\mathrm{HpD}$ on BVDV after 30 min irradiation (residual infectious virus titer) $\left({ }^{*} \mathrm{p}<0.05 ;{ }^{* *} \mathrm{p}<0.01 ;{ }^{* * *} \mathrm{p}<0.001\right)$ 


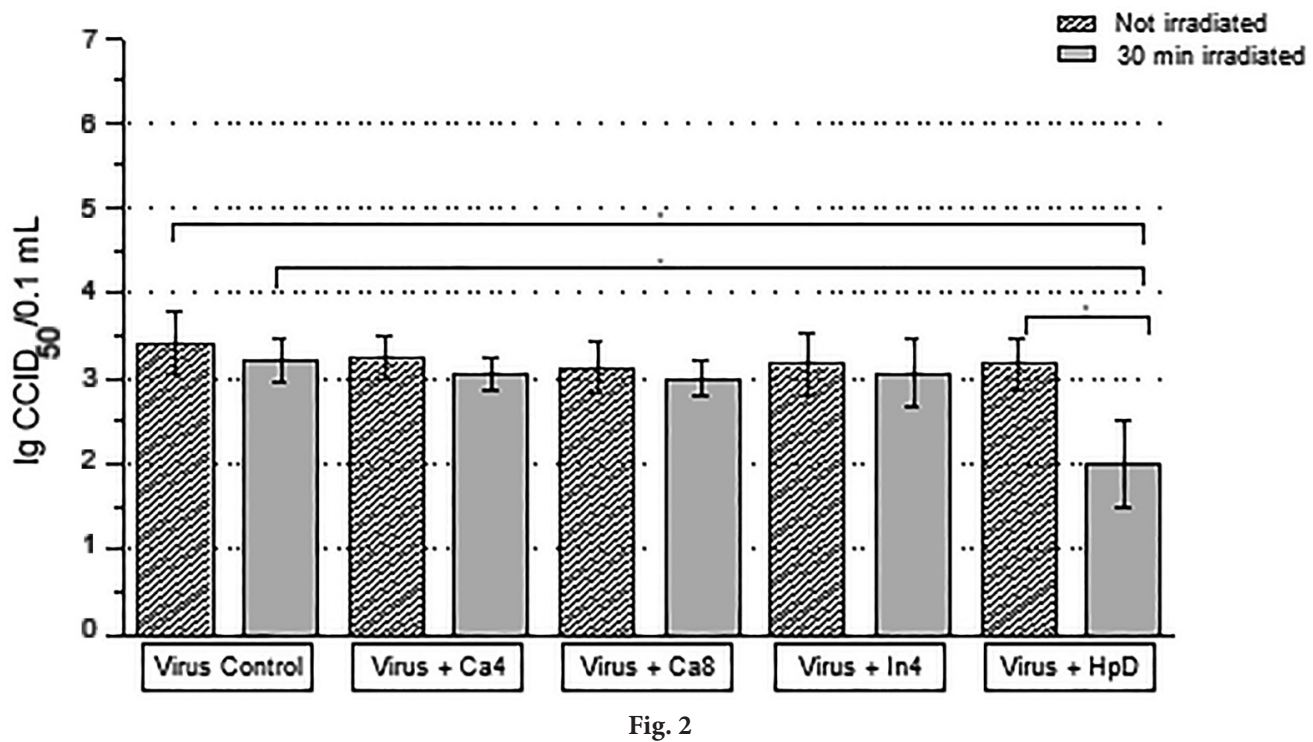

Direct virucidal effect of Ga4, Ga8, In4 and $\mathrm{HpD}$ on influenza virus A/H3N2 after 30 min irradiation (residual infectious virus titer) (" $\mathrm{p}<0.05$ )

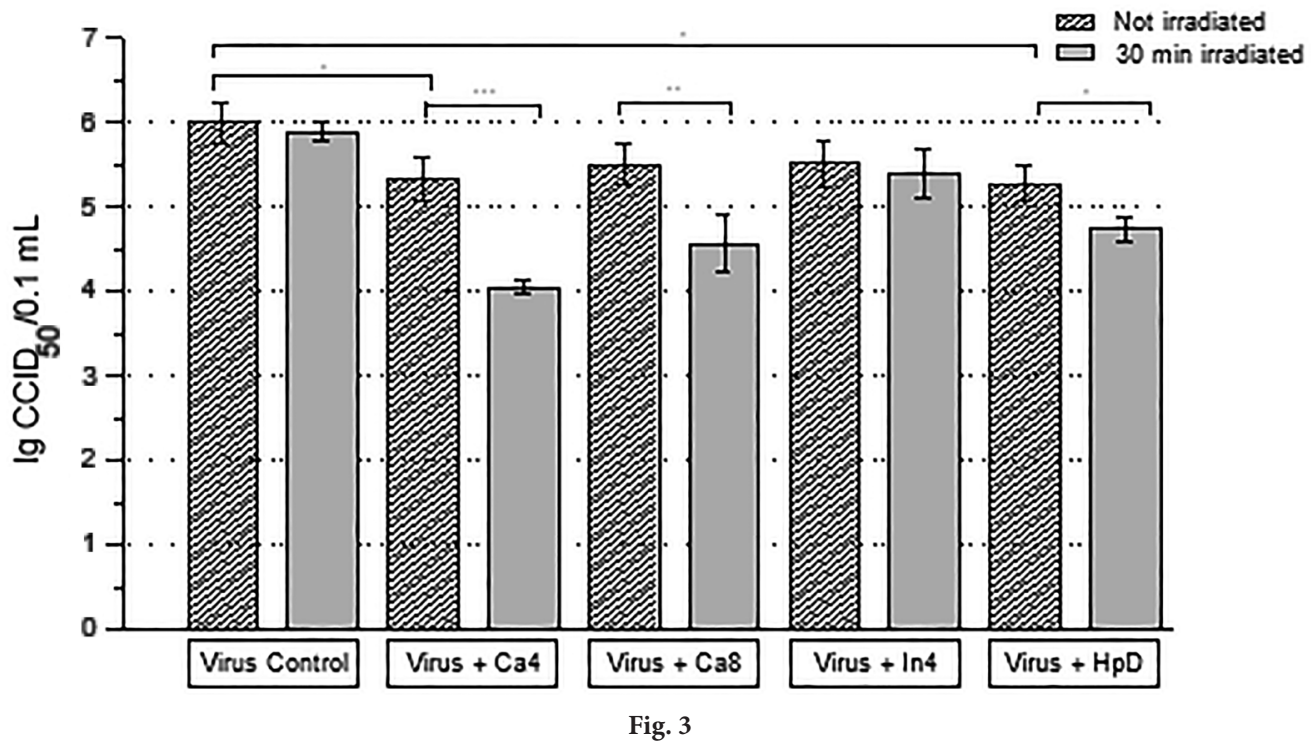

Direct virucidal effect of Ga4, Ga8, In4 and HpD on PV-1 after 30 min irradiation (residual infectious virus titer) ("p $<0.05$; ${ }^{* *} \mathrm{p}<0.01$; *** $\mathrm{p}<0.001$ )

\section{Effect on influenza virus A}

Influenza virus is an enveloped virus with a negative and segmented RNA genome. Surprisingly, the phthalocyanines tested in this study did not significantly influence virus infectivity in the absence of light, nor after irradiation of the samples. Only HpD, which differs in its chemical structure, lowered virus infectivity by less than $1.5 \mathrm{lg}$ (Fig. 2). Irradiation by itself did not influence infectious virus titer.
Non-enveloped viruses, effect on poliovirus 1

PV-1 represents the Enterovirus genus of the Picornaviridae family. These are small, non-enveloped viruses with a positive RNA genome. When irradiated in the presence of the tested photosensitizers, poliovirus titer was diminished by up to approximately $2 \lg$ (Fig. 3). Best effect was detected in the case of Ga4, which lowered infectious virus titer by $\Delta \lg 1.95$, followed by Ga8 ( $\Delta \lg 1.45)$. In 4 did not signifi- 


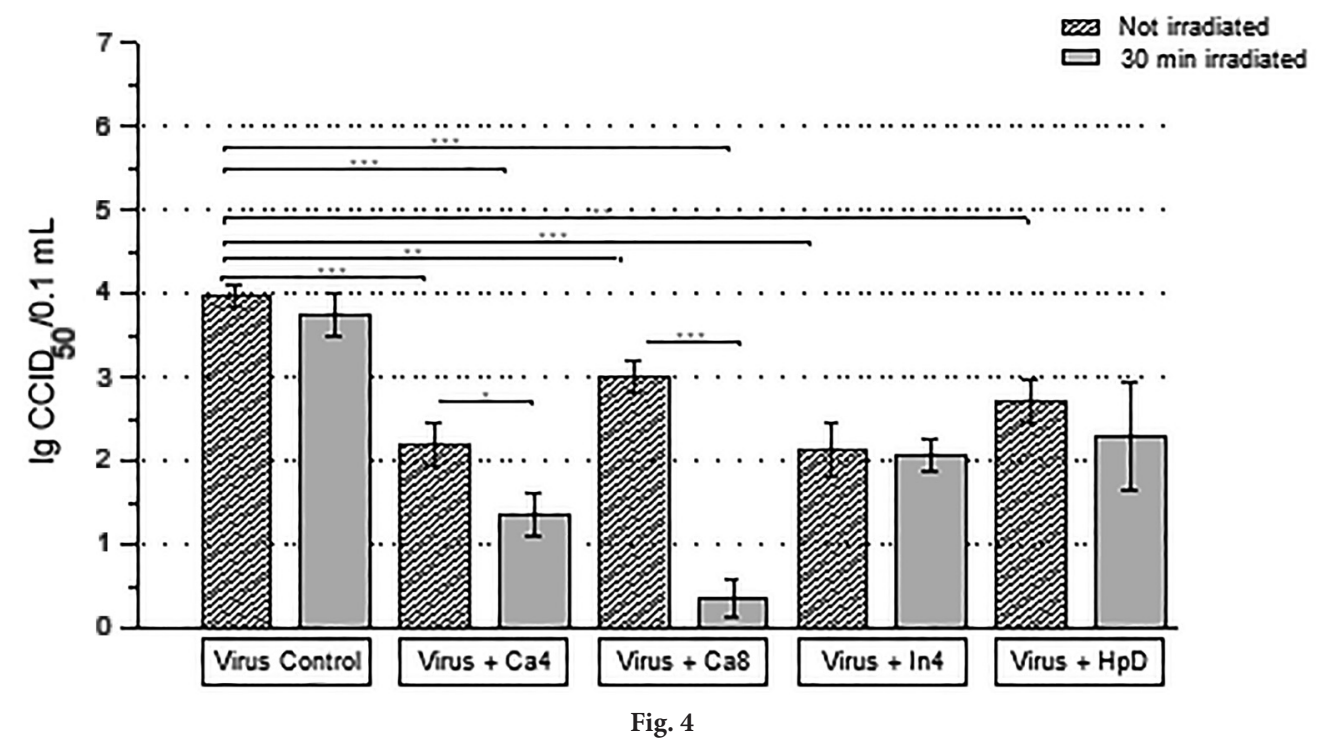

Direct virucidal effect of Ga4, Ga8, In4 and HpD on HAdV-5 after 30 min irradiation (residual infectious virus titer) $\left({ }^{*} \mathrm{p}<0.05 ;{ }^{* *} \mathrm{p}<0.01 ;{ }^{* * *} \mathrm{p}<0.001\right)$

cantly inhibit the virus after irradiation. The presence of the phthalocyanines by themselves in the absence of light did not significantly affect virus infectivity, although Ga4 and $\mathrm{HpD}$ were capable of slightly lowering the infectious virus titer without irradiation.

\section{Effect on human adenovirus type 5}

HAdV5 of the multitudinous Adenoviridae family is a non-enveloped virus with a double stranded DNA genome. Like enteroviruses, these viruses are extremely resistant in the environment. Very interestingly, the tested compounds when only present in the sample and not yet irradiated exerted some virucidal effect $(\Delta \mathrm{lg} \approx 1.8$ for In 4 and Ga4) (Fig. 4). Irradiation additionally contributed to lowering of the infectious virus titer, best revealed in the case of Ga8. The total decrease achieved by Ga8 as compared to the untreated virus control was $\Delta \lg 3.67$ (Fig. 4).

\section{Discussion}

The results obtained in this study characterized new photosensitizers as antivirals. Data from the in vitro investigations could be considered as a first step of the development of the newly synthesized phthalocyanines, mainly Ga4 and $\mathrm{Ga}$, as perspective agents for photodynamic disinfection of blood products.

As a rule, enveloped viruses are more easily inactivated than the non-enveloped ones and the efficacy of inactivation varies according to the type of enveloped viruses (Costa et al., 2012). In our study this was well manifested towards BVDV but, surprisingly, not at all against influenza virus $\mathrm{A}(\mathrm{H} 3 \mathrm{~N} 2)$. While the effect of photosensitizers on BVDV was described in the literature (Ben-Hur et al., 2000), no data on anti-influenza virus effect were found. Evidently, photosensitizing activity on influenza viruses need additional investigations.

As manifested, the phthalocyanines by themselves in the absence of light did not significantly affect PV-1 infectivity, although $\mathrm{Ga} 4$ and $\mathrm{HpD}$ were capable of slightly lowering the infectious virus titer without irradiation. A similar phenomenon with those compounds was observed on BVDV, but the inactivation effect there was much more pronounced. Having in mind that non-enveloped viruses are relatively more resistant to photoinactivation, the results obtained here with $\mathrm{Ga} 4$ and Ga8 deserve special attention.

The fact that HadV-5 and BVDV were inactivated to the greatest extent after irradiation in the presence by Ga8 and approximately $4 \mathrm{lg}$ reduction of the infectious virus titer was achieved in both cases, outlines Ga8 as a very promising photosensitizer.

In conclusion, the photoinactivating potential of Ga4 and Ga8 especially on non-enveloped viruses, human adenovirus in particular, reveals a promise for the development of a virus-inactivating agent with a possible application in hygiene strategies in an environmentally friendly manner.

Acknowledgement. The work was carried out with the financial support of the grant B-02/9-2014 of the National Scientific Fund of Bulgaria. 


\section{References}

Abe H, Wagner SJ (1995): Analysis of viral DNA, protein and envelope damage after methylene blue, phthalocyanine derivative or merocyanine 540 photosensitization. Photochem. Photobiol. 61, 402-409. https://doi.org/10.1111/j.17511097.1995.tb08630.x

Ben-Hur E, Chan WS, Yim Z, Zuk MM, Dayal V, Roth N, Heldman E, Lazo A, Valeri CR, Horowitz B (2000): Photochemical decontamination of red blood cell concentrates with the silicon phthalocyanine PC4 and red light. Dev. Biol. Stan. 102, 149-155.

Berger RS, Papa CM (1977): Photodye herpes therapy - Cassandra confirmed. J. Am. Med. Assoc. 238, 133-134. https://doi. org/10.1001/jama.1977.03280020037019

Borenfreund E, Puerner JA (1985): Toxicity determination in vitro by morphological alterations and neutral red absorption. Toxicology Letters 24, 119-124. https://doi. org/10.1016/0378-4274(85)90046-3

Casteel MJ, Jayaraj K, Gold A, Bell LM, Sobsey MD (2004): Photoinactivation of hepatitis A virus by synthetic porphyrins. Photochem. Photobiol. 80, 294-300. https://doi. org/10.1562/2004-04-05-RA-134.1

Costa L, Faustino MA, Neves MG., Cunha A, Almeida A (2012): Photodynamic inactivation of mammalian viruses and bacteriophages. Viruses 4, 1034-1074. https://doi. org/10.3390/v4071034

Costa L, Tome JPC, Neves MGPMS, Tome AC, Cavaleiro JAS, Cunha A, Faustino AF, Almeida A (2012): Susceptability of non-enveloped DNA- and RNA-type viruses to photodynamic inactivation. Photochem. Photobiol. Sci. 11, 1520-1523. https://doi.org/10.1039/c2pp25156f

Durmus M, Nyokong T (2007): Synthesis, photophysical and photochemical properties of tetra- and octasubstituted gallium and indium phthalocyanines. Polyhedron 26, 3323-3335. https://doi.org/10.1016/j.poly.2007.03.007

Felber TD, Smith EB, Knox JM, Wallis C, Melnik JL (1973): Photodynamic inactivation of herpes simplex: report of a clinical trial. J. Am. Med. Assoc. 92, 223-289. https:// doi.org/10.1001/jama.1973.03220030027005

Gaspard S, Tempete C, Werner GH (1995): Studies on photoinactivation by various phthalocyanines of a free or replicating non-enveloped virus. J. Photochem. Photobiol. B. 31, 159162. https://doi.org/10.1016/1011-1344(95)07198-9

Kaufman RH, Adam E, Mirkovic RR, Melnick JL, Young RL (1978): Treatment of genital herpes simplex virus infection with photodynamic inactivation. Am. J. Obstet. Gynecol. 132, 861-869. https://doi.org/10.1016/00029378(78)90713-5

Mantareva V, Angelov I, Wöhrle D, Dogandjiska V, Dimitrov R, Kussovski V (2011b): Water-soluble phthalocyanine complexes of $\mathrm{Ga}(\mathrm{III})$ and $\mathrm{In}(\mathrm{III})$ in the photodynamic inactivation of pathogenic fungus. Proc. SPIE 7747 (774712), 1-9.

Mantareva V, Kussovski V, Angelov I, Whörle D, Dimitrov R, Popova E, Dimitrov S (2011a): Non-aggregated Ga(III)- phthalocyanines in the photodynamic inactivation of planktonic and biofilm cultures of pathogenic microorganisms. Photochem. Photobiol. Sci. 10, 91-102. https:// doi.org/10.1039/B9PP00154A

Mohr H, Lambrecht B, Schmitt H (1993): Photo-inactivation of viruses in therapeutic plasma. Dev. Biol. Stand. 81, 177-183.

Moor ACE, Wagenaars-van Gompel AE, Hermanns RCA, van der Meulen J, Smit J, Wilschut J, Brand A, Dubbelman TMAR, van Steveninck J (1999): Inhibition of various steps in the replication cycle of vesicular stomatitis virus contributes to its photoinactivation by AlPcS4 or Pc4 and red light. Photochem. Photobiol. 69, 353-359. https://doi.org/10.1562/0031-8655(1999)069<0353:IOVSIT>2.3.CO;2

Neurath AR, Strick N, Jiang S (1994): Rapid prescreening for antiviral agents against HIV-1 based on their inhibitory activity in site-directed immunoassays. Approaches applicable to epidemic HIV-1 strains. Antivir. Chem. Chemother. 4, 207-214. https://doi.org/10.1177/095632029300400403

Perdrau JR, Todd C (1933): The photodynamic action of methylene blue on certain viruses. Proc. Roy. Soc. Lond. B Biol. Sci. 112, 288-298. https://doi.org/10.1098/rspb.1933.0011

Reed LJ, Muench H (1938): A simple method of estimating fifty percent endpoints. Am. J. Hygiene 27, 493-497.

Rywkin S, Ben-Hur E, Malik Z, Prince AM, Li Y-S, Kenney ME, Oleinick NL, Horowitz B (1994): New phthalocyanines for photodynamic virus inactivation in red blood cell concentrates. Photochem. Photobiol. 60, 165-170. https:// doi.org/10.1111/j.1751-1097.1994.tb05085.x

Santus R, Grellier P, Schrevel J, Maziere JC, Stoltz JF (1998): Photodecontamination of blood components: advantages and drawbacks. Clin. Hemorheol. Microcirc. 18, 299-308.

Schagen FHE, Moor ACE, Cheong SC, Cramer SJ, van Ormondt $\mathrm{H}$, van der Eb AJ, Dubbelman TMAR, Hoeben RC (1999): Photodynamic treatment of adenoviral vectors with visible light: an easy and convenient method for viral inactivation. Gene Ther. 6, 873-881. https://doi. org/10.1038/sj.gt.3300897

Schultz EW, Krueger AP (1928): Inactivation of Staphylococcus bacteriophage by methylene blue. Proc. Soc. Exp. Biol. Med. 26, 100-101. https://doi.org/10.3181/00379727$\underline{26-4158}$

Smetana Z, Malik Z, Mendelson E, Ben-Hur E (1997): Treatment of viral infections with 5 -aminolevulinic acid and light. Laser. Surg. Med. 21, 351-358. https://doi. org/10.1002/(SICI) 1096-9101(1997)21:4<351::AIDLSM6 $>3.0 . \mathrm{CO} ; 2-\mathrm{P}$

Wainwright M (2004): Photoinactivation of viruses. Photochem. Photobiol. Sci. 3, 406-411. https://doi.org/10.1039/ $\underline{\mathrm{b} 311903 n}$

Wong T-W, Huang H-J, Wang Y-F, Lee Y-P, Huang Ch-Ch, Yu Ch-K (2010): Methylene blue-mediated photodynamic inactivation as a novel disinfectant of enterovirus 71 . J. Antimicrob. Chemother. 65, 2176-2182. https://doi. org/10.1093/jac/dkq301 